Bol. Acad. peru. leng. 62.2017 (205-220)

\title{
Nuevas caricaturas y un texto no conocido de Abraham Valdelomar
}

\section{New caricatures and an unknown text by Abraham Valdelomar}

\author{
SERVAIS THISSEN \\ Investigador belga independiente
}

\section{Resumen:}

En este artículo se rescata una serie de caricaturas nuevas de Abraham Valdelomar así como «Horas de lucha», un texto del Conde de Lemos que hasta la fecha no ha sido compilado como parte de su obra. Con la publicación de estas ilustraciones y artículo pretendo contribuir a la sistematización de la obra completa de Valdelomar.

\section{Abstract:}

This article rescues a series of new caricatures of Abraham Valdelomar as well as "Horas de lucha" ('Hours of struggle'), a text of the Conde de Lemos (Earl of Lemos, aristocratic pseudonym) that up to now has not been compiled as part of his work. With the publication of these illustrations and this paper, it is intended to contribute to the systematization of the complete work of Valdelomar. 
Palabras clave: Abraham Valdelomar, literatura peruana, caricatura, crónica periodística.

Keywords: Abraham Valdelomar, Peruvian literature, caricature, journalistic chronicle.

Recibido: 31/08/2017

Aceptado: 15/11/2017

\section{Nuevas caricaturas de Valdelomar}

Hace unos años tuve la oportunidad de conseguir un volumen que contenía varias revistas antiguas de Lima, con dos números de La Sotana, de 1909 (se trata de un «semanario semi-surgente de caricaturas, festivo, político y anticlerical»), así como diez números de Fray Simplón, de 1909, cuyo director era Juan de Dios Bedoya (es también un «semanario de caricaturas, festivo, político, anticlerical»). Se trata, muy probablemente, de la continuación de La Sotana, cuya vida fue efímera. Lo más importante del volumen son los 76 números de Fray K. Bezón: uno de 1907, otros de 1908 y 1909, y el último de 1910. Su director era Francisco A. Loayza.

Por el sello que figura en varias páginas, este volumen perteneció a un señor J. Fidel Fernández, de la localidad de Cora Cora.

Grande era mi interés de buscar allí caricaturas de Valdelomar, pues sabía que colaboró en la revista Fray K. Bezón: en varios estudios lo mencionaban, pero nunca había visto una de esas caricaturas; además, esta revista era inubicable en las bibliotecas. Revisé minuciosamente todo el volumen, sin encontrar una sola caricatura con la firma de Valdelomar; pero, después 
de un examen más detenido, he llegado a la conclusión de que hay un buen número de caricaturas que le pertenecen, por la similitud de los trazos y temas que él trató en otras publicaciones, como por ejemplo, la revista ilustrada Cinema.

Algunas caricaturas son casi idénticas; a veces tienen la mención «Smart», seudónimo de Valdelomar que ignoraba. Vale la pena detenernos a analizar algunas, a modo de ejemplo, para determinar las autorías. En el número 100 de Fray K. Bezón, del 26 de diciembre de 1908, aparecen las caricaturas de «Tres abogados»: Antonio Miró Quesada, Bernardino Pérez y Rafael Grau (imagen 1). En el número 13 de la revista Cinema, también de fines de diciembre, encontramos el rostro de Bernardino Pérez, con características muy similares (imagen 2), así como en la portada del número 12, del 19 de diciembre de 1908 (imagen 3): en los dos últimos casos, las caricaturas están firmadas por Valdelomar:

\section{Imagen 1}

Caricatura de Valdelomar publicada en Fray K. Bezón № 100, con el seudónimo Smart, el 26 de diciembre de 1908.

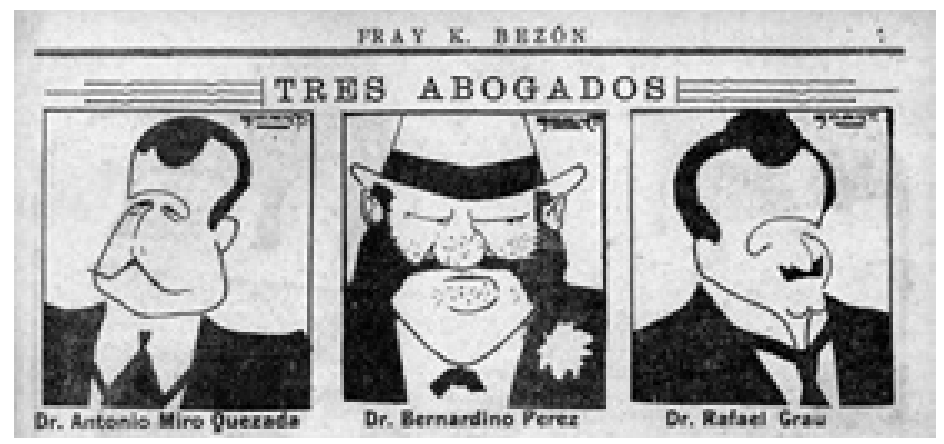


Imagen 2

Caricatura de Valdelomar publicada en la revista Cinema No $^{\circ} 13$, diciembre de 1908.

\section{LOS AGUINALDOS} non VAEDKEOAER.

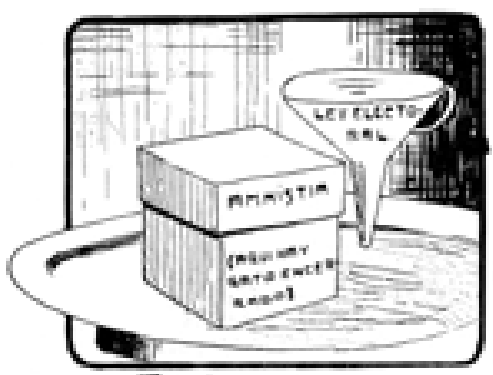

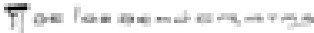
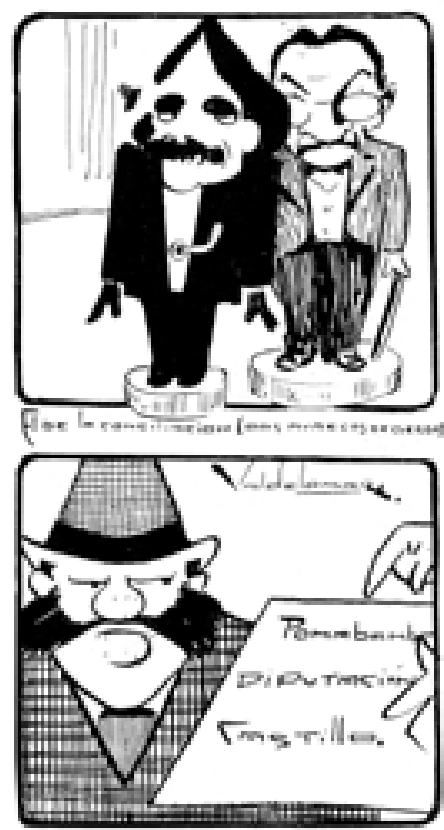

Cl se rerez
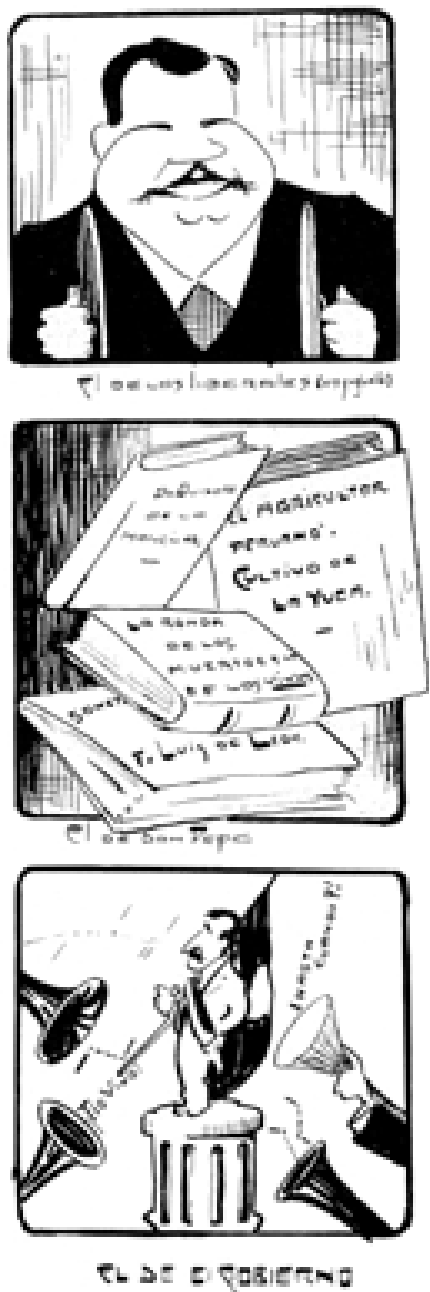
Imagen 3

Caricatura de Valdelomar publicada en la portada de la revista Cinema No 13 , el 19 de diciembre de 1908.
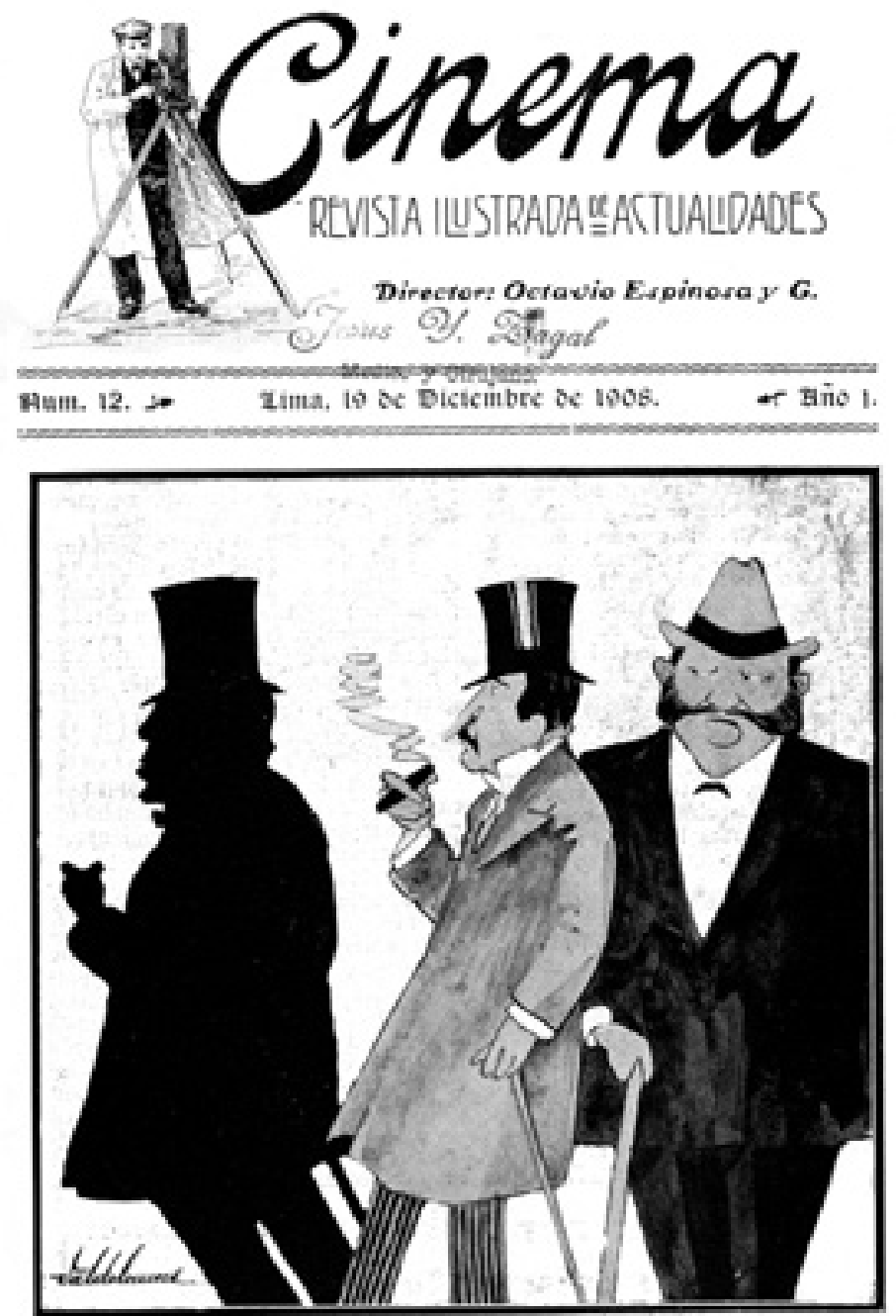

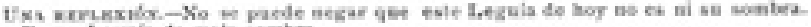

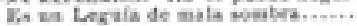


En cuanto al retrato de Miró Quesada, hay uno muy parecido en la falsa carátula del número 6 de Cinema (imagen 4); lo mismo podemos constatar al comparar los retratos del senador Grau, en la carátula del número 4 de Cinema (imagen 5): se trata, con toda evidencia, de la misma pluma y del mismo autor. Observemos:

\section{Imagen 4}

Caricatura de Valdelomar publicada en la falsa carátula de la revista Cinema No 6, el 7 de noviembre de 1908.

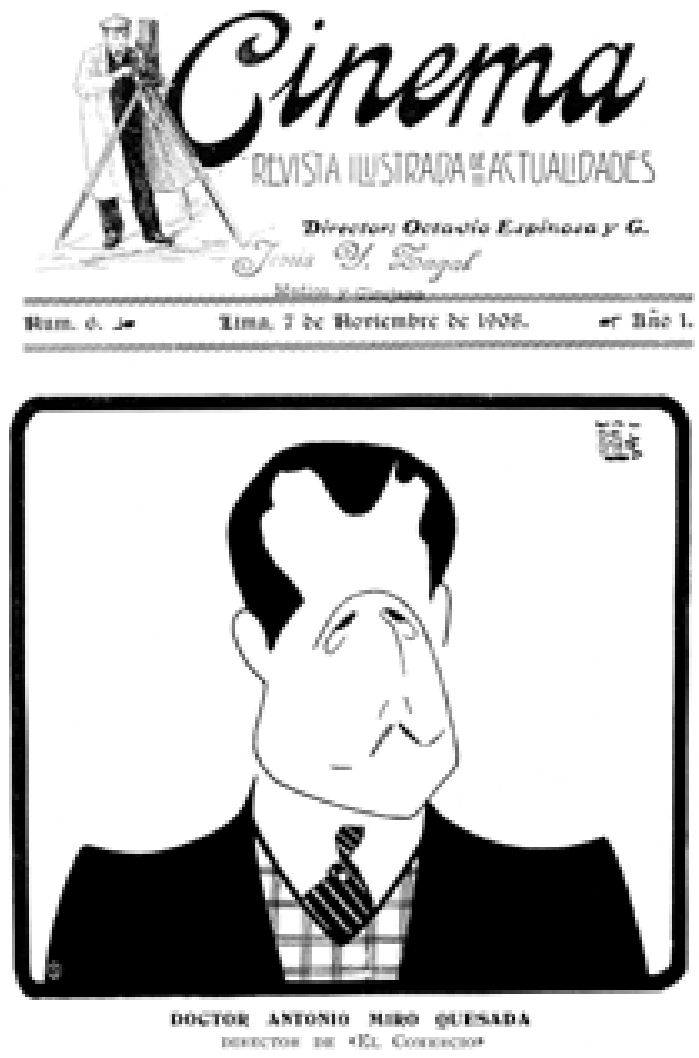


Imagen 5

Caricatura de Valdelomar publicada en la portada de la revista Cinema No 4, el 24 de octubre de 1908.
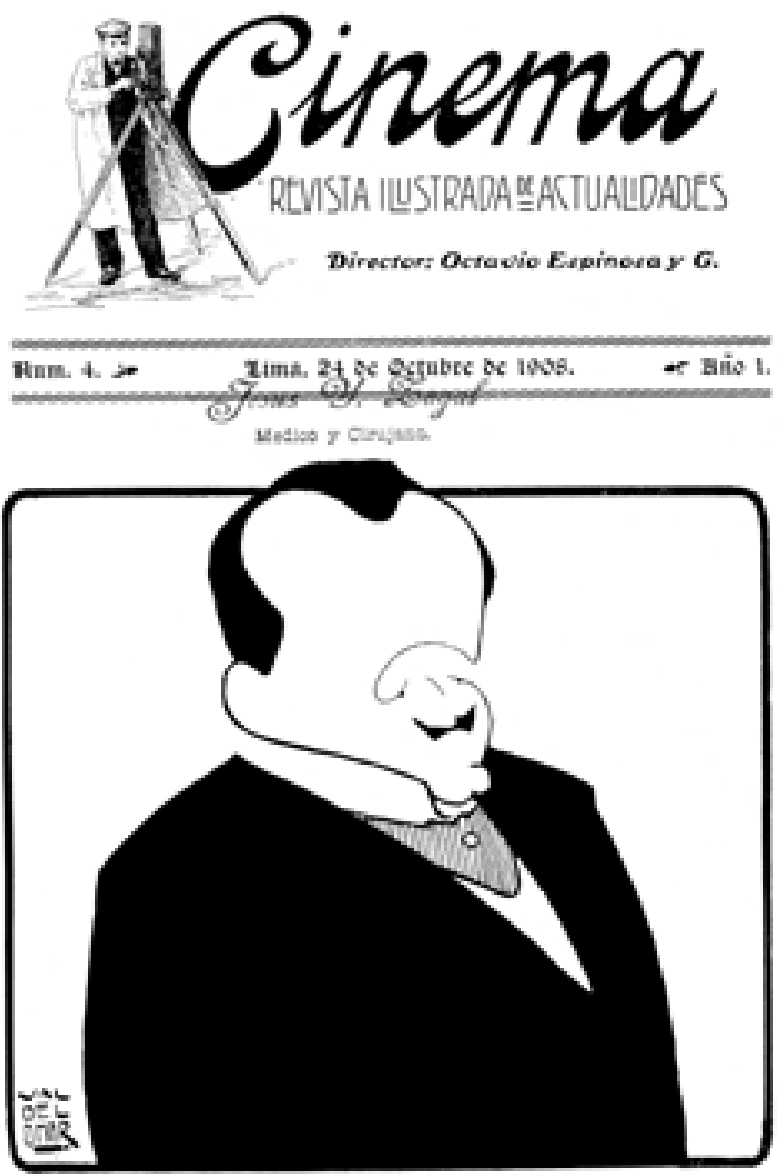

El sikor Girau, Alpatade per Cotabambas.

Numerosas son las caricaturas, en Fray K. Bezón, que pertenecen a Valdelomar, muchas veces sin firma alguna, otras con el seudónimo «Smart». En el número 
129, del 28 de julio de 1908, hay una página entera, con nueve personajes caricaturizados (imagen 6): el de Víctor Criado y Tejada - el primero de la segunda fila- es, con toda evidencia, similar al que figura en la página 133 del número 6 de Cinema (imagen 7):

\section{Imagen 6}

Caricatura de Valdelomar publicada en Fray K. Bezón № 129, el 28 de julio de 1908.

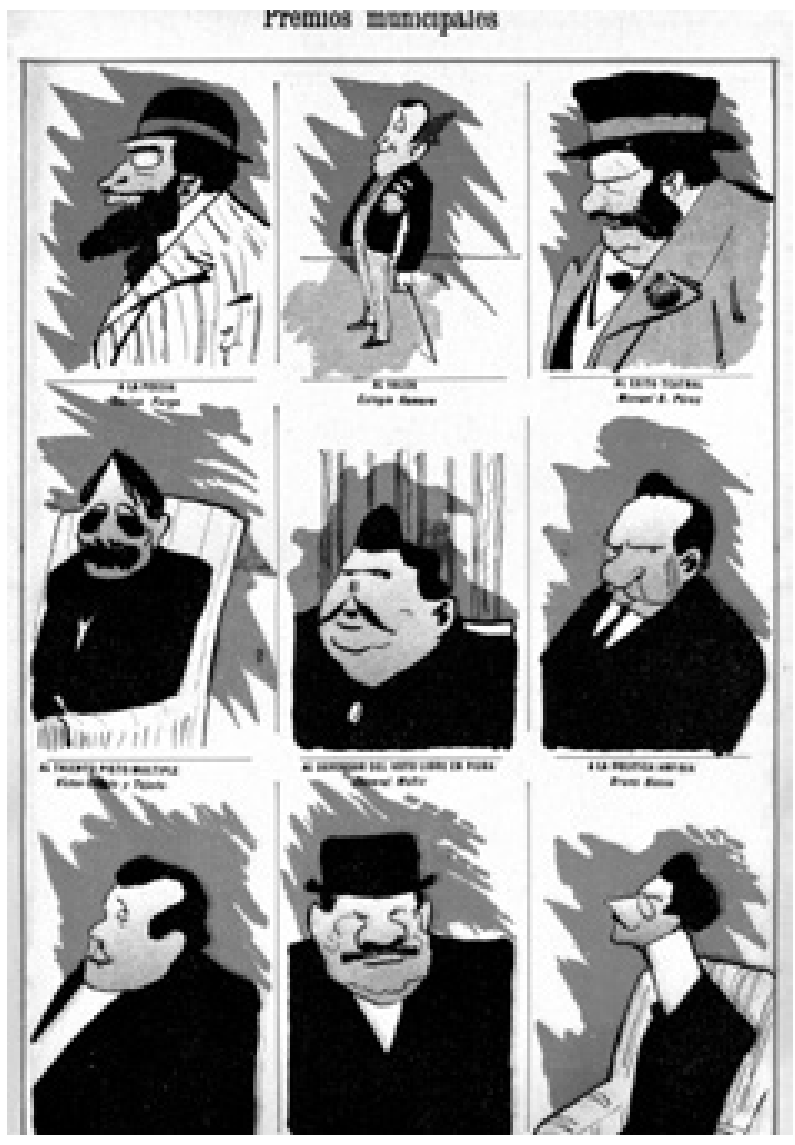


Caricatura de Valdelomar publicada en la revista Cinema № 6 , el 7 de noviembre de 1908.

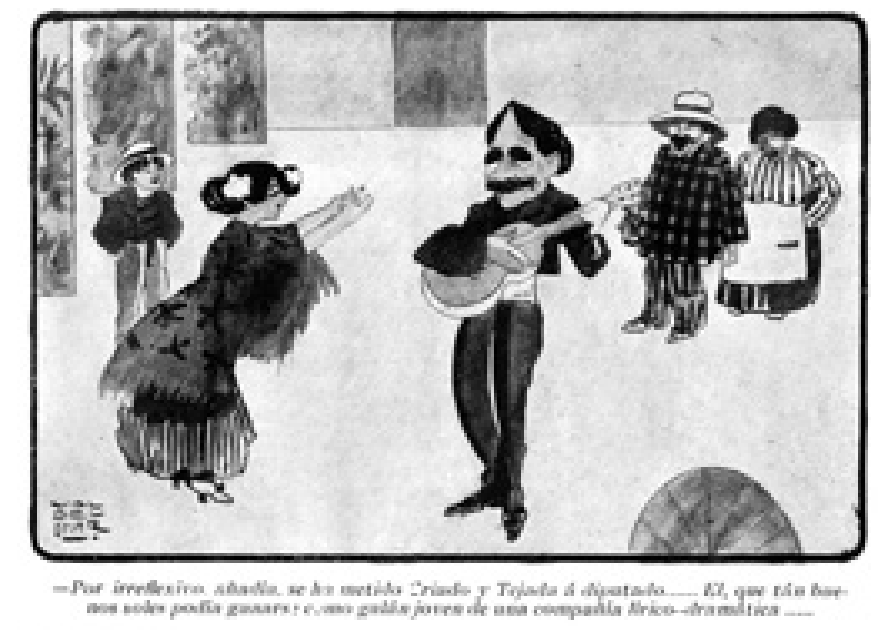

¿Por qué Valdelomar no firmaba con nombre propio sus caricaturas en Fray K. Bezón? La respuesta muy probable es que esta revista era de tendencia marcadamente anticlerical; basta ver las carátulas, los artículos y las caricaturas para darse cuenta de la virulencia con que descargaban sus baterías contra el clero y la Iglesia en general. Valdelomar no quería herir la susceptibilidad de su madre, ferviente católica, que no hubiera tolerado que su hijo predilecto participara en semejante empresa. Es de notar que las caricaturas de Valdelomar nunca han tratado temas eclesiales, y se limitaban más bien al ámbito político y cultural de la vida limeña.

El diccionario de seudónimos de Alberto Tauro no señala a «Smart». ¿Qué significado puede tener? Dejo a los especialistas de Valdelomar dilucidar esta incógnita. 
Por lo general, los artículos que aparecen en la revista son firmados con seudónimos; abriendo una página al azar, encuentro: «Ignoto - K. Pote - Clarinete - K. Mote - Fray P. Pino - Falco»; y los caricaturistas más citados son «Polar», «Chambón», «Gorón» y «Smart».

El mismo Valdelomar dijo que entre los años 1906 y 1910, con Málaga Grenet, «llenaron de dibujos todos los periódicos ilustrados de la capital». En este primer decenio, muchas eran las revistas humorísticas que se publicaban en Lima. La misma revista Fray K. Bezón señala varias veces que en 1909 «pasaron a mejor vida»: Don Quijote, Monos y Monadas, Verde y Verde, Pero Grullo, La Sotana, La Sanguijuela, Kikiriki, Lima en Broma, Don Guiseppe, La Campana, Gedeón, El diablo predicador, Blanco y Negro, etc. Es probable que en varias de estas publicaciones se puedan encontrar caricaturas de Valdelomar. Es tarea pendiente.

\section{Valdelomar: un texto no conocido}

En el número 129 de la revista Fray K. Bezón, del año 1909 , encontré un solo texto en prosa firmado por Valdelomar, del 28 de julio, titulado «Horas de lucha»; es un comentario de la obra de Manuel González Prada, publicada a fines del año anterior. Este texto no figura en ninguna de las ediciones de las obras de Valdelomar, preparada por Pinto, Sánchez, Silva-Santisteban, para citar solo algunos. Ciertamente, se trata de un texto importante de Valdelomar, tanto por la fecha temprana como por el contenido, que nos revela varias facetas del temperamento del escritor. Confiesa su gran admiración por González Prada y cuánta influencia ha ejercido el maestro sobre su pensamiento: «cuántas veces... he 
buscado con los ojos del alma un luchador!», y que ha sido «demasiado influenciado por su escrito».

Transcribo el texto completo del artículo de Valdelomar, tal como apareció (con el apellido Gonzáles con 's' en vez de ' $z$ '):

\section{«HORAS DE LUCHA»}

Hace ocho meses, más ó menos, que se anunció por una casa editora, que tuvo el valor de lanzarla al público, la obra del príncipe de nuestros pensadores, don Manuel Gonzáles Prada.

Demasiado influenciado por su escrito, no pretendería, ni podría llevar á cabo una crítica ¿qué digo? ¡una crítica, emitir un juicio?

Hay una gran diferencia entre esa intelectualidad optimista y de propaganda, que paga un ministerio, y la intelectualidad sincera de un asceta, libre de influencias perniciosas. Puede decirse que son tan antagónicas como la propaganda del bien y la propaganda del mal.

Gonzáles Prada es pesimista, pero pesimista de nosotros, desconfía y nada espera de nuestra raza. Y hay razón para desconfiar de una juventud demasiado guiable. La generación intelectual que hoy se inicia, nació al calor de los artículos de Gonzáles Prada, en las tranquilas aulas de los colegios. Había que esperar; era una juventud que prometía, pensadora, honrada y entusiasta, y más tarde cuando debía reforzar sus ideas en las Universidades, se puso en contacto con una intelectualidad degenerada e hipócrita, influenciada por los viejos maestros, enemigos terribles del reformador. $Y$ fueron asimilándose á ellos y se perdió hoy esa juventud popular porque no ha sido fiel.

Hay razón para desconfiar, porque nuestros entusiasmos no brotaron cuando Gonzáles Prada tocó con la vara mágica de sus ideas nuevas y grandes el fondo de nuestras conciencias puras: todavía éramos jóvenes. 
Hoy la reacción sería imposible.

¡Cuántas veces viendo pasar los grupos numerosos de jóvenes universitarios, he buscado con los ojos del alma un luchador! ¡Cuántas veces he querido encontrar un Mesías Pero los jóvenes pasan.

El no llega, èl no aparece... y la manada de almas va pasando: hacia un fin oscuro y horrible, hacia una lejana ciudad de burgueses donde se divertirán con fonógrafos, con cajas de música y con teatros gignol.

Separado de la política por no profesar las ideas de los partidos, solo, abandonado aparentemente, Gonzáles Prada tiene un poder absoluto sobre estas almas timoratas, que dicen pensar.

Se le teme. Se evitan sus frases y sus artículos, como evitamos escuchar, sin poderlo, la voz de la conciencia.

Porque Gonzáles Prada no es una mano que solicita: es un índice que acusa.

Los diarios no lo bombardearon porque el libro no les era grato. Además, cuando se emprende labor de regeneración moral, cuando se analizan y se dicen los más secretos sentimientos; los que como él acusan á un país en sus hombres y en su vida moral, no necesitan esa labor de propaganda barata, ni prestigio al calor de un suelto de crónica. Las generaciones hablan más que los periódicos.

Su libro es una colección de artículos y discursos desde el año 1898 hasta la fecha: sin embargo, no pasan de veinte. Páginas brillantísimas, oraciones perfectamente áticas, frases eternas, he ahí un conjunto del libro de Gonzáles Prada.

¡Qué gran verdad! ¡Qué profundidad de análisis! Y ¡qué moral! Cuando critica á nuestros partidos. ¡Cuántos de nuestros hombres públicos, moralmente muertos por una frase, verán en las líneas de este hombre, el juicio de las edades futuras!

No es su obra una doctrina absolutista ni de intransigencia, es el producto de una alma generosa, humana, demasiado humana. 
Es el primer pensador de nuestra época.

Libre de adornos y de frases pomposas, sin amaneramiento ni galas, solo, con su credo como LE PENSEUR de Rodin; su conducta descansa sobre las doctrinas inamovibles y grandiosas de que está convencido. Jamás cambió de partidos ni profesó ideas antagónicas. Tiene una percepción clara y definida de todas las cosas y de todos los hombres.

Hé aquí una frase suya que no morirá nunca:

«En Esparta nadie se enfurecía ante una mujer sin vestido; en París nadie se escandalizaba con una estátua desnuda. Solo en la Roma de los Pontífices, se cubría con hojas de parra los cadáveres destinados á los estudiantes de medicina».

«Los jueces modernos condenarían á Friné pero tratando de ir á seducirla en su prisión».

Toda una casta, casi una generación de hipócritas y de tartufos, echada á perder con un plumazo!

$Y$ hablando en otro de sus artículos dice:

«No hay dos reinos distintos -el de Dios y el de los hombres- sino el reino de la justicia. A la añeja teoría de "Al César, lo que es del César» sucede hoy el principio de: Al hombre lo que es del hombre. Y ¿qué es del hombre? La tierra. ¿A qué tiene derecho? A la felicidad. Todo ser humano tiene derecho no solo al agua y al pan, al abrigo, sino al amor, al confortable, al goce, al saber, en resúmen: a la vida más intensa y más extensa.

Y más abajo:

«Según la justicia divina, son muchos los llamados y pocos los elegidos; según la justicia humana todos son los llamados, todos los elegidos».

Y así es su libro.

Luchando con el ambiente que los conservadores le han hecho, su libro se ha comprado y se ha llevado oculto como un fruto prohibido; se ha adquirido mirando á todas partes antes de cogerlo, como se comete un pecado; se buscó, pero no se aplaudió, ni se discutió siquiera. 
Un joven intelectual, amigo mío, gran admirador de Nieztche, escribía al derredor del retrato del pensador alemán: «Este perfil debía grabarse en todas las monedas del universo!!

Este mismo hombre había puesto sobre el libro de Gonzalez Prada:

«En este libro debían aprender á leer todas las generaciones.» Tal vez si así nuestros hijos no se avergonzarían de nosotros......!

ABRAHAM VALDELOMAR

Lima, 1909. 


\section{Anexo}

«Horas de lucha»; texto en prosa firmado por Valdelomar, publicado en Fray K. Bezón No 129, pp. 2-3, el 28 de julio de 1909.

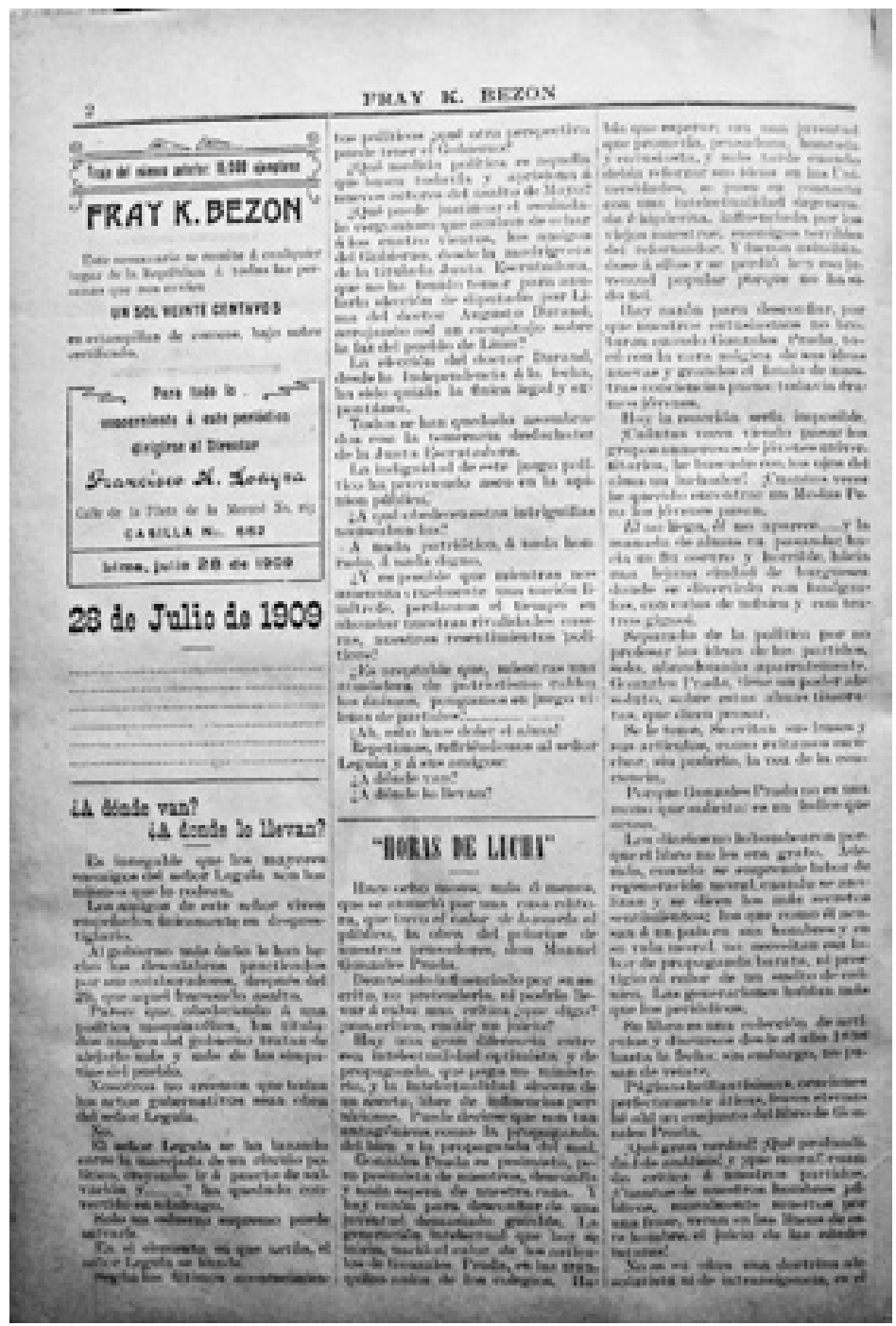




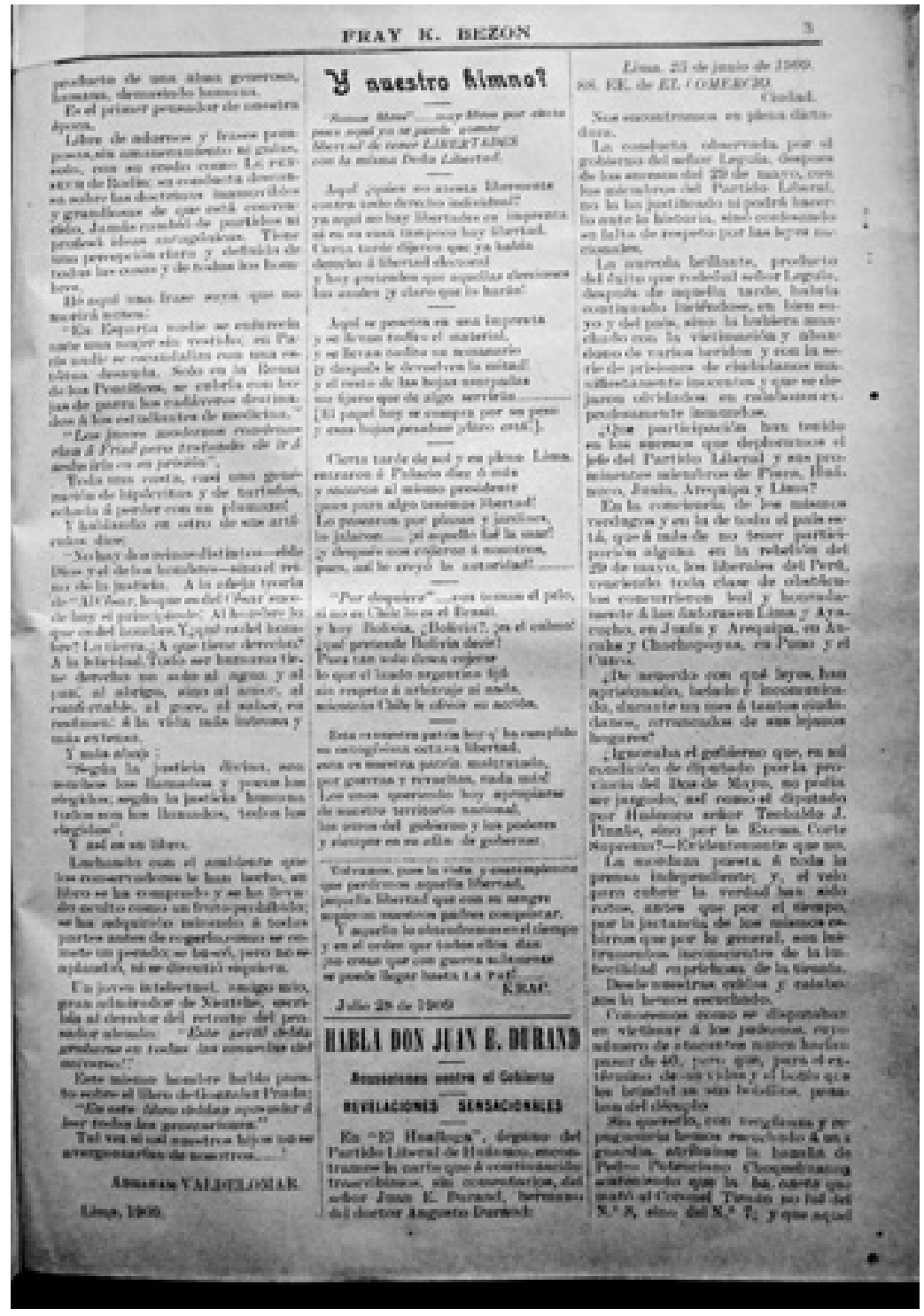

